\title{
ROBUST DESIGN OF A FUTURE 100\% RENEWABLE EUROPEAN ENERGY SUPPLY SYSTEM WITH HYDROGEN INFRASTRUCTURE
}

\author{
$1,2^{*}$ Dilara Gulcin Caglayan, ${ }^{1}$ Heidi U. Heinrichs, ${ }^{1}$ Martin Robinius, ${ }^{1,2}$ Detlef Stolten \\ ${ }^{1}$ Institute of Energy and Climate Research - Techno-economic Systems Analysis (IEK-3) \\ Forschungszentrum Juelich GmbH, 52425 Juelich, Germany \\ ${ }^{2}$ RWTH Aachen University, Chair for Fuel Cells, Faculty of Mechanical Engineering, \\ Eilfschornsteinstraße 18, D-52062 Aachen, Germany \\ *Corresponding author e-mail: d.caglayan@fz-juelich.de
}

\begin{abstract}
In light of the latest trends in global installed capacities, the importance of variable renewable energy sources (VRES) to future energy supply systems is evident. Despite this, the inherent intermittency of VRES remains an obstacle to their widespread adoption. Green hydrogen is often suggested as an energy carrier that can account for this in a sustainable manner. In the analysis, a robust European energy system in the context of 2050 and with $100 \%$ VRES energy supply is designed through an iterative minimal cost-optimization approach that ensures robust security of supply over 38 weather-year scenarios (1980-2017). The impact of spatial VRES variability is factored in by defining exclusive VRES groups within each optimization region and, from this, it can be seen that higher numbers of groups in each region offer cheap electricity generation locations to the optimizer and thus decrease the total annual cost of the system. Beyond this, the robust system design and impact of inter-annual variability is identified by iteratively combining the installed capacities of different system designs obtained by applying 38 historical weather years. The robust system design outlined here has significantly lower capacities in comparison to the maximum regional capacities obtained in the first round of optimization.
\end{abstract}

Keywords: Renewable energy systems; energy supply systems; hydrogen pipelines; power-tohydrogen.

\section{INTRODUCTION}

Despite the shift towards renewable energy sources [1,2], the intermittency of variable renewable energy sources (VRES) such as wind and solar remains an issue that could be solved by employing chemical energy carriers [3]. Such chemical energy carriers can be produced at peak power generation periods and then used in other sectors such as transport (as fuel) [4], electricity (for grid balancing) or industry (as feedstocks) enabling so-called 'sector coupling' [5-8]. Hydrogen is considered the most promising alternative energy source owing to its carbon-free nature and wide variety of uses $[9,10]$. Nevertheless, some issues related to the role of hydrogen are still unsolved [10,11].

Up until now, several studies have modeled hypothetical hydrogen infrastructures on a national level such as for the United Kingdom [12], France [13], Italy [14] and Germany [6,15,16] or the energy trading link between countries [17]. Focusing on larger regional scopes such as Europe, the number of analyses with large shares of renewables decreases compared to those with a national focus. It should be noted that some European studies do not consider alternative energy carriers at all, whereas others consider them to some extent. A greenfield approach to a future European energy system was employed by Reichenberg et al. [18], in which different shares of renewables were assessed. A large scale renewable energy system in future context was conducted by Aboumahboub et al. [19] globally, while focusing on the European system 
as well. In addition, Brown et al. [20] highlighted the role of electricity transmission and concluded that flexibility and transmission played a significant role in the system. Beyond the power sector, the importance of sector-coupling in a future European energy system has been emphasized by several studies [21,22]. The definition of regions in a future European energy system design and its impacts were assessed by Siala and Mahfouz [23]; a similar methodology was then applied in a future European energy system, which is then coupled with a multiregional input-output model by Siala et al. [24]. A fully renewable European energy system was reported to be feasible by Zappa et al. [25]. Meanwhile, a comparison of storage technologies (grid, hydrogen or hydropower) was conducted by Steinke et al. [26] in an exemplary European energy system, and yet a combination of all of these technologies was lacking in the analysis. Moser et al. [27] focused on storage technologies by conducting sensitivity analyses in a European energy system model. Including hydrogen storage and conversion in their analysis, Bussar et al. [28-30] designed a potential future European energy system; nevertheless, the transmission of hydrogen between regions was not addressed.

In addition to the aforementioned analyses conducted directly in the context of future energy systems, transitional paths for energy system design have been addressed by a number of studies. For instance, Löffler et al. [31] modeled the transition of the European energy system so that the target of staying below $2{ }^{\circ} \mathrm{C}$ would be achieved. Similarly, Schlott et al. [32] assessed the European energy system transformation between 1970 and 2100. In turn, Child et al. [33] analyzed European energy system design, while Bogdanov et al. [34] conducted a similar analysis at a global level on the basis of transformation.

High spatial and temporal resolution, the future characteristics of technologies within the energy system's design and consideration of low-cost hydrogen technologies were addressed by Caglayan et al. [35]. In their assessment, Europe was divided into 96 regions and optimized with hourly-resolved renewable and demand profiles. Although the unpredictable nature of hourly generation profiles of renewables in the context of 2050 were evaluated by comparing energy system designs based on different weather years [36,37], a systematic approach has not been proposed to overcome these variations in the design. Therefore, the variations in system design with respect to different weather years must be scrutinized in order to obtain a robust design that ensures security of supply. To the authors' knowledge, no existing studies have covered all of these aspects together in a fully renewable European energy supply system.

In this study, an iterative approach is employed in order to design a robust European energy supply system based on $100 \%$ renewable energy that incorporates a hydrogen infrastructure in the context of 2050. For this purpose, an optimization model that minimizes the total annual cost (TAC) is built with an hourly temporal resolution [35]. Furthermore, Europe is divided into 96 regions with subgroups of VRES technologies within each region in order to afford higher spatial resolution. The results involve the optimal capacities for the technologies considered in the system design, as well as the optimal operation of these. The potentials and simulations for wind and solar energy in these regions are estimated by using future-oriented VRES technologies. Significant variations are observed in the system designs for different weather years, ranging from 1980 to 2017 . On the basis of these, a robust design is attained by using an iterative approach over individual system designs for different years. These results can then be used as an indicator to understand the roles of individual countries in a fully renewable energy supply system. 


\section{METHODOLOGY}

The analysis is performed by using the open source optimization framework, the Framework for Integrated Energy System Assessment (FINE) [15]. The objective function of the problem is minimizing the system's TAC. From a regional perspective, Europe ${ }^{1}$ is separated into 96 regions. Although hourly temporal resolution is used, time series aggregation [38] is employed in some model runs to simplify the optimization problem (cf. Figure 4). In these simplified model runs, 30 typical days are assumed to be sufficient to represent the entire year. The impact of the temporal complexity reduction by time series aggregation and of modeling the European energy system by using a single weather year was previously< investigated by Caglayan et al. [35] in detail.

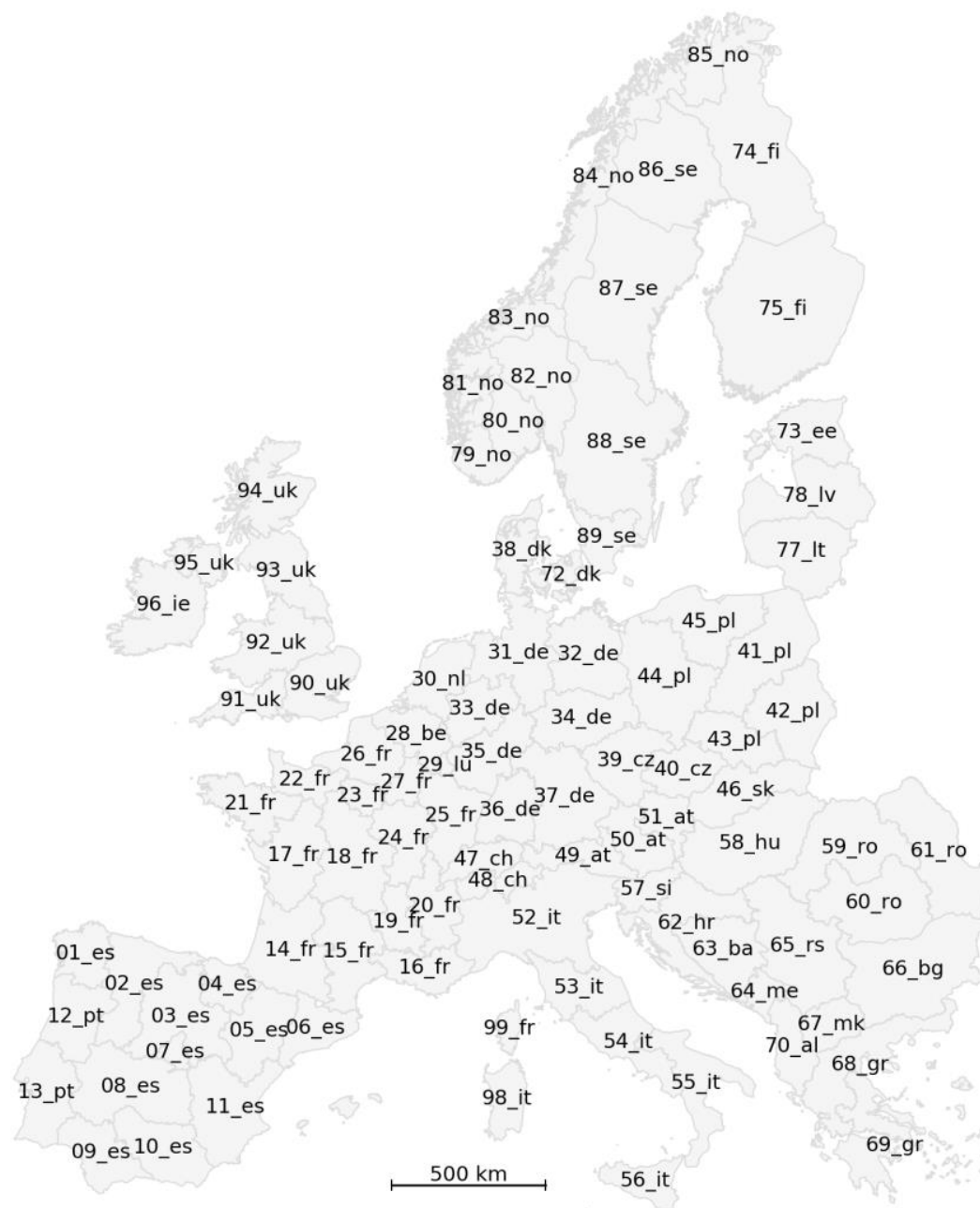

Figure 1 Regional definition employed in this work.

The technologies and their interactions with corresponding commodities within a region are shown in Figure 2. The techno-economic parameters for demand, generation, conversion, storage and transmission technologies are defined exogenously as input parameters in the optimization problem, and are provided in the supplementary material. Despite the greenfield approach for 2050 employed in this analysis, the capacities of run-of-river and hydropower

\footnotetext{
${ }^{1} \mathrm{~A}$ regional definition of Europe with corresponding region names is provided in the supplementary material.
} 
(pumped-hydro storage and reservoirs) plants are assumed to have the same values as reported in 2015. Electricity demand was derived using the same approach as the E-Highway study [39]. However, electricity demand for battery-electric vehicles and plug-in hybrid vehicles was excluded, as fuel cell-electric vehicles are involved in the system with $75 \%$ market penetration. Existing driving behavior, annual driving distance and the total number of passenger vehicles are used to derive annual hydrogen demand, which is then projected onto the hourly profile of fueling stations. The technical storage capacity of salt caverns for each region are obtained from the study of Caglayan et al. [40].

With respect to electricity generation, onshore wind, offshore wind, open-field photovoltaics (PV), run-of-river and biomass combined heat and power (CHP) plants are included. The simulation of wind and PV technologies is performed by using historical weather data from the reanalysis dataset, Modern-Era Retrospective analysis for Research and Applications (MERRA) [41] by using an open-source Python package "RESKit - Renewable Energy Simulation toolkit for Python" [42-45]. In order to determine the maximum capacity that can be installed in each region, land eligibility analyses are performed individually for onshore and offshore wind following the eligibility constraints reported by Ryberg et al. [43] and Caglayan et al. [45], Additionally, the conversion of hydrogen to electricity and vice-versa is addressed by several conversion technologies such as open-cycle gas turbines (OCGT), combined-cycle gas turbines (CCGT) and electrolysis. Hydrogen transmission is taken into account by estimating the shortest path between regions from a candidate grid derived from the combination of roads, railways and existing natural gas infrastructure. Finally, electricity transmission is taken into account when considering high voltage alternative current (HVAC) and high voltage direct current cables (HVDC), the capacities of which are derived by using the same method as employed in the E-Highway study [39].

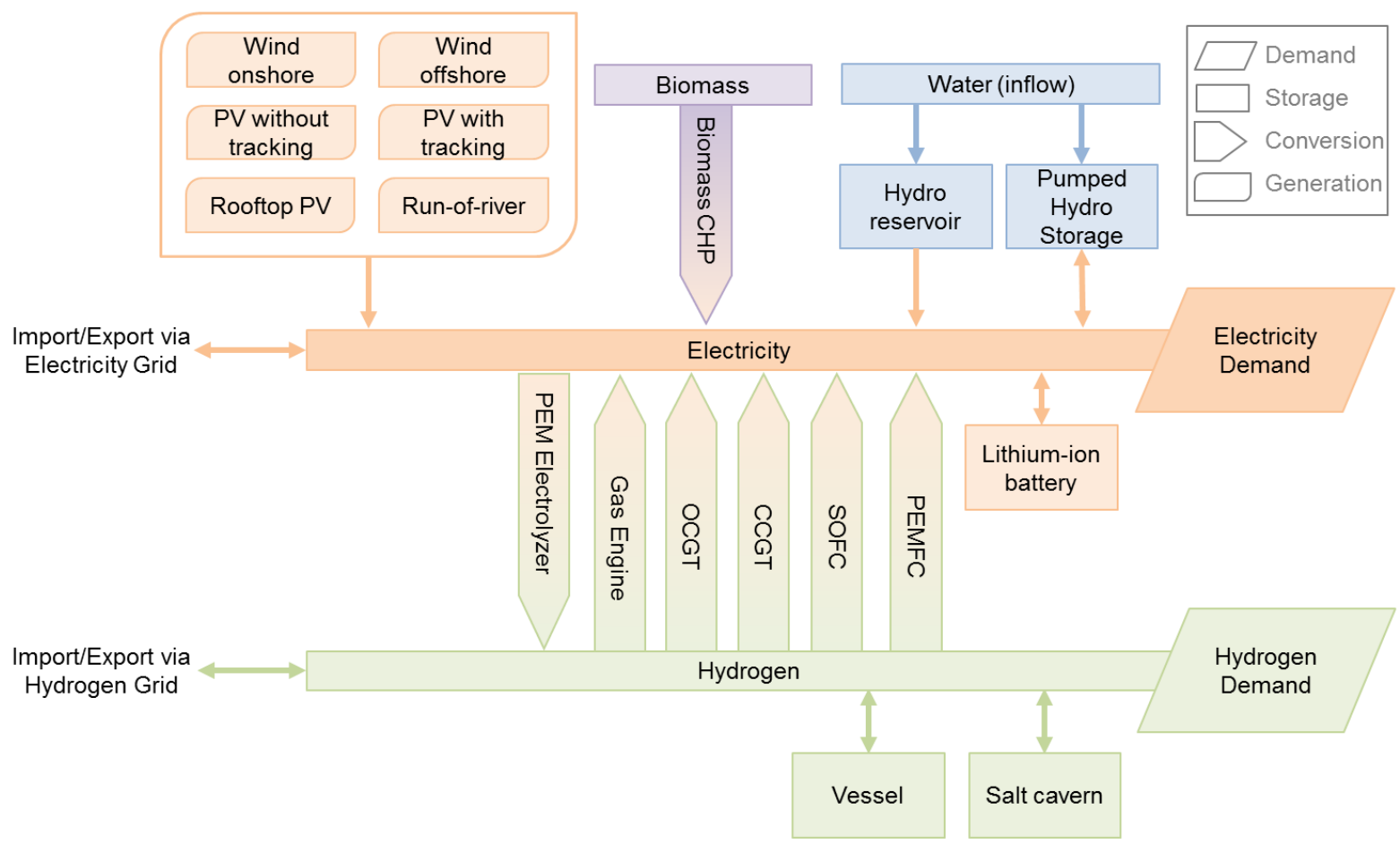

Figure 2 Representation of technologies and their interactions within a region in the energy system 


\subsection{Detailed Modeling of Wind and PV Energy by Grouping}

The number of regions and technologies considered in the energy system design is limited due to the tractability issues of optimization problems. Simplification of the system while maintaining modeling detail is possible by grouping the VRES placements by criterion. In doing so, spatial resolution can be increased while keeping the number of regions constant. The definition of several groups of technologies instead of averaging enhances their accuracy. In other words, utilizing different groups provides higher spatial resolution with slightly increased model complexity for a larger number of regions. A generation technology for VRES is defined in the energy system model by a generation time series and the maximum capacity to be installed within a region where each VRES group is defined as an independent technology.

As an example, Figure 3 shows turbine locations in North Rhine-Westphalia, Germany, and their their corresponding generation time series in 2015 in order to emphasize the impact of grouping on the generation time series. It can be seen in the upper figure that peak power is not attained most of the time, as the average time series is affected by turbines with low generation. As a result, the utilization of high-generation locations is not possible when a single time series is used in the model. The lower figure shows the same time period in the same region when only four turbine groups are defined by their average LCOE. As can be seen from the generation time series, the time series shown in purple covers the peak power generation time periods better than single generation time series, whereas the time series shown in blue represents the low generation locations. Although the overall behavior has still not been fully captured, the technology can be modeled in a more realistic way, with a larger number of groups (the ideal modeling occurs when the number of groups is equal to the number of turbines in that region). In this analysis, 60 groups per renewable technology grouped by average LCOE are employed as a compromise between model accuracy and computational effort. 


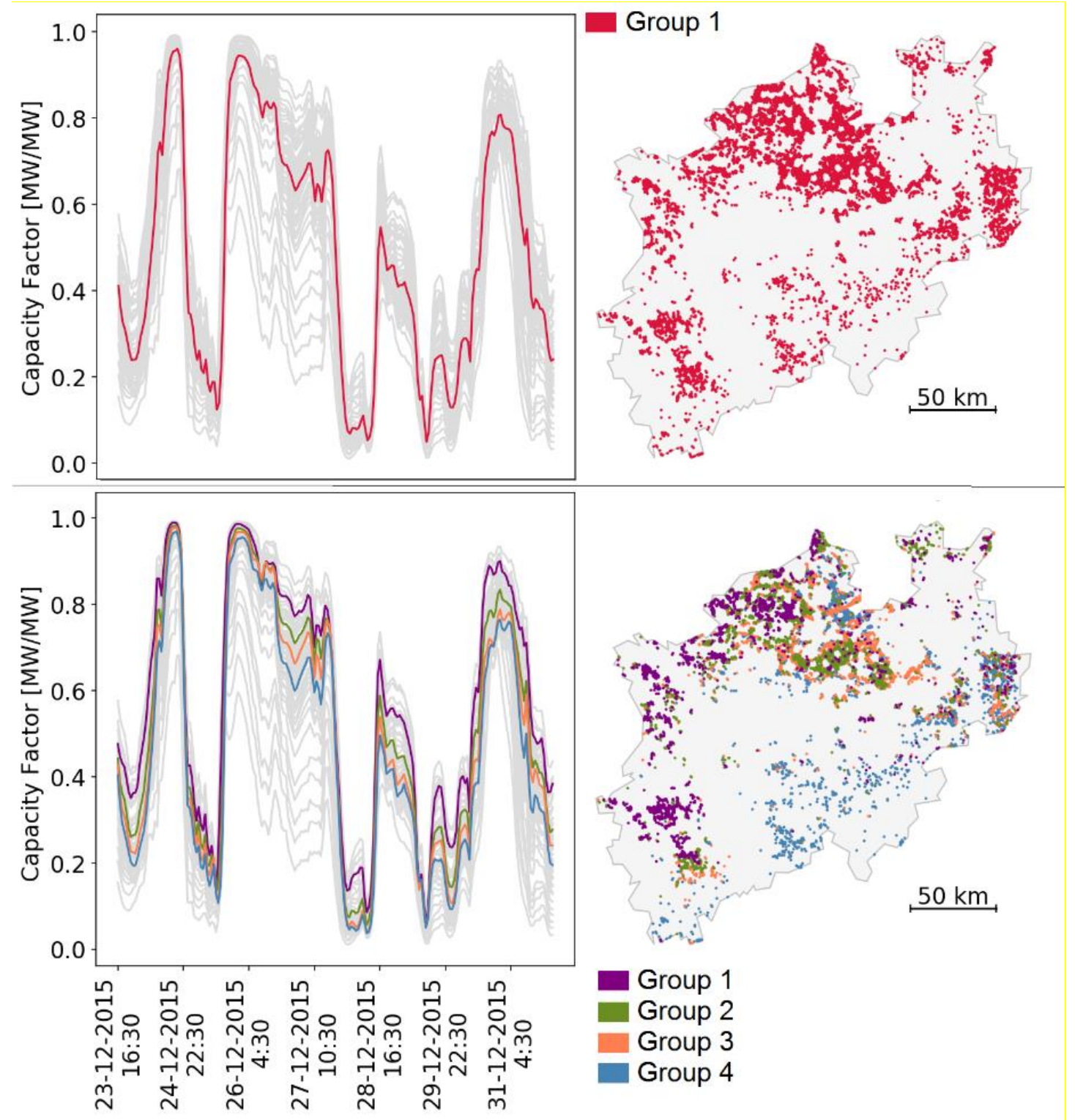

Figure 3 Distribution of onshore turbine locations in North Rhine-Westphalia, Germany, with corresponding generation time series (weather year: 2015) and different groups that are classified by an equal division of percentiles of the turbine's LCOE; (upper) for single grouping and (lower) four-turbine groups.

\subsection{Iterative Approach for Robust Energy System Design}

The design of the energy supply system differs with respect to the generation time series of VRES technologies (i.e., historical weather year). Thus, an iterative method is developed to achieve a robust system design while keeping the costs as low as possible. This approach consists of three main steps, as depicted in Figure 4., which are as follows: optimization of the overall system, adjusting the biomass CHP plant capacities to capture extreme weather periods and, finally, optimizing the operation of these technologies. Each iterative step consists of 38 model runs conducted by all weather years between 1980 and 2017. In the optimization of the overall system, 38 optimal capacities of each technology for each weather year are averaged 
and defined as the minimum capacity; afterwards, the system is optimized with these new constraints. The individual iterations in this work can be explained in simple terms as follows:

Iteration 0: Results of the impact of different weather years obtained with the technical potential of renewables defined as the maximum installable capacities in the optimization problem of each weather year. The system is independently optimized for different weather years.

Iteration 1-3: At each iterative step, the maximum capacities for each technology from the previous iteration results are defined as the technical limit in each region. Moreover, the average capacities are set as the minimum capacity that must be installed. In the case of a hydrogen pipeline, minimum capacities are only set for the pipeline connections repeating $50 \%$ of the time. For the optimizations, 30 typical days are used. As the total annual cost did not change by more than $1 \%$ compared to the previous iteration, Step 1 consists of four iterations (Iterations 03 ) in this system analysis.

Iteration 4: All of the capacities except biomass CHP plants are fixed at "Iteration 4". The assumed capacities are the average optimal capacities of technologies amongst all of the weather years estimated at "Iteration 3". Optimizations are conducted without time series aggregation, as the fixed capacities decreased the complexity and memory requirements. The purpose of this step is to scale the biomass CHP plant capacities in order to capture extreme periods (days) that could not be captured with the use of 30 typical days. The main objective of this step is to scale the biomass plant's capacity to ensure security of supply in the extreme periods.

Iteration 5: The design results obtained in "Iteration 4" are analyzed to identify the maximum biomass CHP plant capacity in each region across all of the weather years. Afterwards, as with all the other technologies, biomass CHP plant capacities are set to these maximum values obtained in "Iteration 4". In this iterative step, the main purpose is to find the optimal operation of technologies with the design capacities proposed for the robust system design. Therefore, the average results over all weather years for curtailment, losses and transported commodities are estimated by using all of the results indicated in "Iteration 5 ".

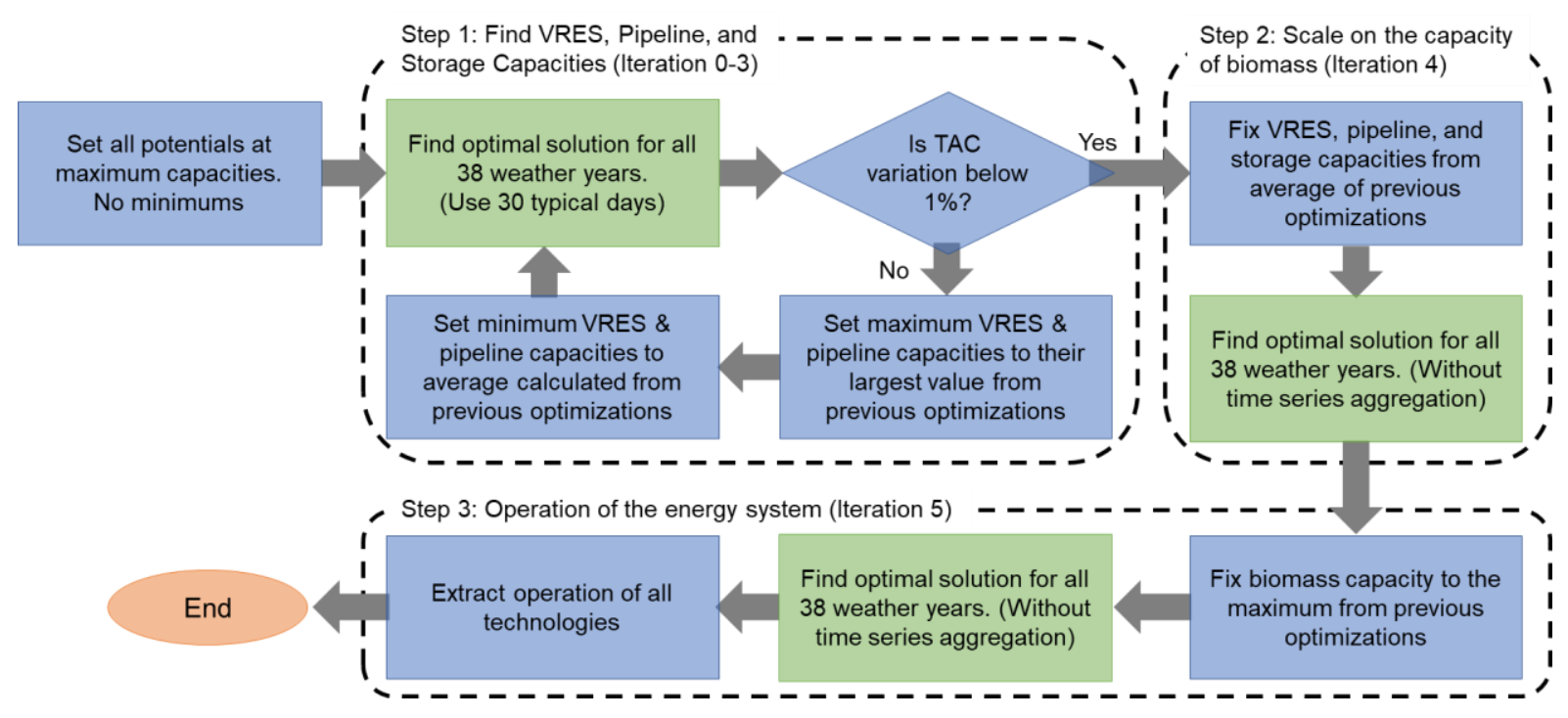

Figure 4 Algorithm used to derive the robust energy system design to ensure security of supply. 


\section{RESULTS \& DISCUSSION}

This section can be classified into two main parts, the first of which shows the importance of the detailed modeling of VRES technologies. The impact of the detailed VRES technology modeling on an exemplary system design, the weather year of which is assumed to be 2015, is shown by creating groups for each technology, as explain in Section 2.1. After investigating the number of groups to be used in the analysis, the robust design was attained by applying the iterative approach explained in Section 2.2, with the system design assessed as the second main part of the results section. The presented results are compared against the existing European energy scenarios available in the literature and presented in the supplementary material.

\subsection{Impact of Grouping VRES Sources}

For each model run, the number of groups in each region and each VRES technology is assumed to be the same. For instance, having 60 groups indicates that there are 60 onshore wind technology units, 60 offshore wind technologies and 60 open-field PV technologies with and without tracking, corresponding to a total of 240 VRES technologies considered across all regions. The number of groups for each VRES technology is kept constant in order to avoid bias towards the particular technology. For example, keeping all technologies within a single group except onshore wind energy influences the optimizer in favor of onshore wind energy technologies, as high potential locations would be preferred over the competitive technologies due to the latter's lower fidelity.

The maximum number of groups is defined as 90 for two reasons: less significant variations beyond 90 groups and a drastic increase in the solution time. Although the solution times in VRES grouping analysis are not comparable to each other because of the calculations performed in the same computational nodes, they are mentioned in order to offer insight into the increase. The solution times of the problems with 60, 72 and 90 VRES groups are 28.6 hours, 85.6 hours and 163.4 hours (nearly 7 days), respectively. ${ }^{2}$

Figure 5 shows the optimal European capacities of VRES technologies and the total annual cost with respect to the different number of groups defined in each independent calculation. Focusing on the optimal capacities, a decreasing trend in the installed capacities of VRES technologies is evident, especially between 1 and 10 groups, which could be explained by the averaging of the time series. Nevertheless, the same behavior is also observed in offshore wind turbines and PV panels. The optimal capacity increases with a lower number of groups in order to supply the demand through the smoother generation time series. The smoother time series are not capable of covering the peak generation periods and exhibit lower levels of generation due to averaging. This is avoided by introducing as many groups as possible so that peak generation time periods are not compensated by locations with low generation. Therefore, the optimizer chooses to install VRES technologies starting from these groups with high-generation locations, and in cases where the capacity in that group is not enough, the following groups with relatively lower generation locations are chosen. Overall, optimal capacity remains more or less the same after a certain number of groups, which is nearly 10 in this case.

When the total annual cost is analyzed for a different number of groups, it can be seen that biomass is especially chosen in the case of single and double groups. As the number of groups increases, the share of biomass in the total annual cost decreases because locations generating

\footnotetext{
2 The computations are distributed across the IEK-3 cluster. The cluster has 10 compute nodes with 72 Intel $(R)$ Xeon(R) Gold 6154 CPU @ 3.00GHz cpus, and 15 compute nodes with Intel(R) Xeon(R) Gold 6144 CPU @ 3.50GHz cpus.
} 
electricity more cheaply than biomass emerged owing to the higher fidelity of the grouping. Therefore, these cost-competitive locations are utilized in the optimization instead of biomass; this issue will be discussed in further detail in the discussion of Figure 6, as this behavior can be observed better at a national scale rather than within the cumulative variations. Similarly to the optimal European capacities, variation in the total annual cost decreases with a higher number of groups. Nevertheless, slight changes in the shares of on-/offshore wind turbines and open-field PV systems without tracking can still be observed. Hence, the optimal capacity distribution should be investigated in order to understand these slight variations and ensure that the system design does not drastically change.
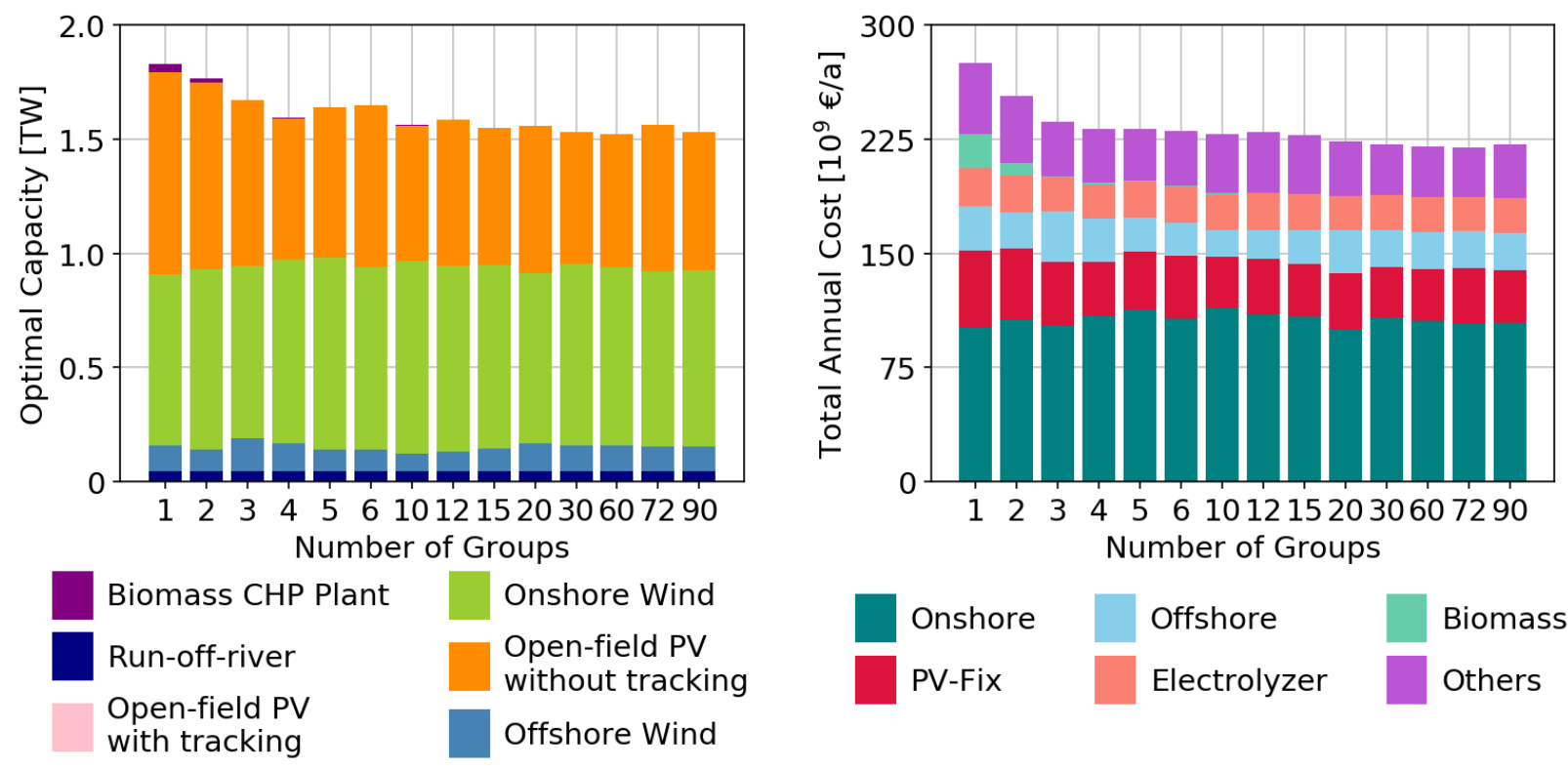

Figure 5 Optimal European capacities and corresponding total annual cost with respect to a different number of groups ${ }^{3}$

In order to determine the number of groups, regional capacities and whether or not these change should be investigated. investigated. While the results do not vary significantly on the European scale as discussed earlier, regional capacities may alter with respect to different numbers of groups. Therefore, the optimal national capacities of VRES technologies are shown in Figure 6 , in order to display the results summarized for all regions and check if the capacities vary with respect to the number of groups. It must be noted that although open-field PV with tracking is introduced in the plot, it was not selected by the optimizer, primarily because of its higher cost compared to the non-tracking variant.

As discussed briefly with respect to the optimal European capacities, an increase in the number of groups results in a decrease in the overall installed capacity. For example, the use of 3 VRES groups instead of a single one decreases the optimal capacity in Ireland from $98 \mathrm{GW}$ to $22 \mathrm{GW}$, which is due to the competitiveness of the technologies grouped in the surrounding regions. Introducing more groups reveals the high-generation locations in these neighboring regions, which become cost-competitive with the cheap onshore locations observed in Ireland. In this example, Denmark experiences a decrease in optimal capacity by $15 \mathrm{GW}$ between single and 3 VRES groups. Similar behavior but with an opposite trend can be observed in Hungary and

\footnotetext{
${ }^{3}$ Single group represents the state-of-art in the literature, which includes the average generation time series of all the locations within the region.
} 
Slovenia for open-field PV without tracking and Norway, the Netherlands and Lithuania for onshore wind energy. By unveiling these high-generation locations, the capacity distribution changes, such as the relationship between northern and southern Greece. With more VRES groups, the optimal capacity of onshore wind energy increases in northern Greece, which then affects the optimal capacity of open-field PV without tracking in the southern part of the country. In order words, high-potential onshore wind locations in northern Greece, which are established by using higher numbers of groups, are more favorable to the energy system than some of the PV locations in southern Greece. This is mainly due to the use of an optimization model to design the energy system, as it seeks to reduce the total annual cost.

In the United Kingdom and the Netherlands, offshore wind energy has become cost-competitive owing to the impact of grouping. This cost-competitiveness results from variation in the investment cost of wind turbines within the region rather than a significant increase in the generation of offshore wind turbines. As the maritime boundaries of these two countries have large areas extending long distances from the shore, expensive wind turbines increase the average investment cost of offshore wind energy in these regions. Especially in countries with a large area extending far from the shore, the investment cost can reach $4000 € \mathrm{~kW}^{-1}$ because of the electrical infrastructure cost of the turbines driving up the overall cost. For example, the average specific investment cost for offshore wind turbines in the Netherlands is $2800 € \mathrm{~kW}^{-1}$ for the overall capacity of $149.7 \mathrm{GW}, 42.3 \mathrm{GW}$ of which has an average cost of $2060 € \mathrm{~kW}^{-1}$ because of closer proximity to shore. Therefore, with the introduction of 3 groups, the specific investment cost is decreased by nearly $30 \%$, along with the maximum allowable capacity. In the case of Belgium, as the maritime area is small and the maximum available capacity of offshore wind energy in the country is utilized in different group scenarios due to the low average specific investment cost (nearly $2000 € \mathrm{~kW}^{-1}$ ). In some regions, such as Poland and Estonia, a switch between onshore and offshore wind energy is apparent. This is caused by the impact of grouping and change in the specific investment costs of onshore and offshore wind energy solutions. In such regions, these two technologies might become cost-competitive and slight changes in their cost or generation might induce switching of the optimal capacity of the individual technologies. 


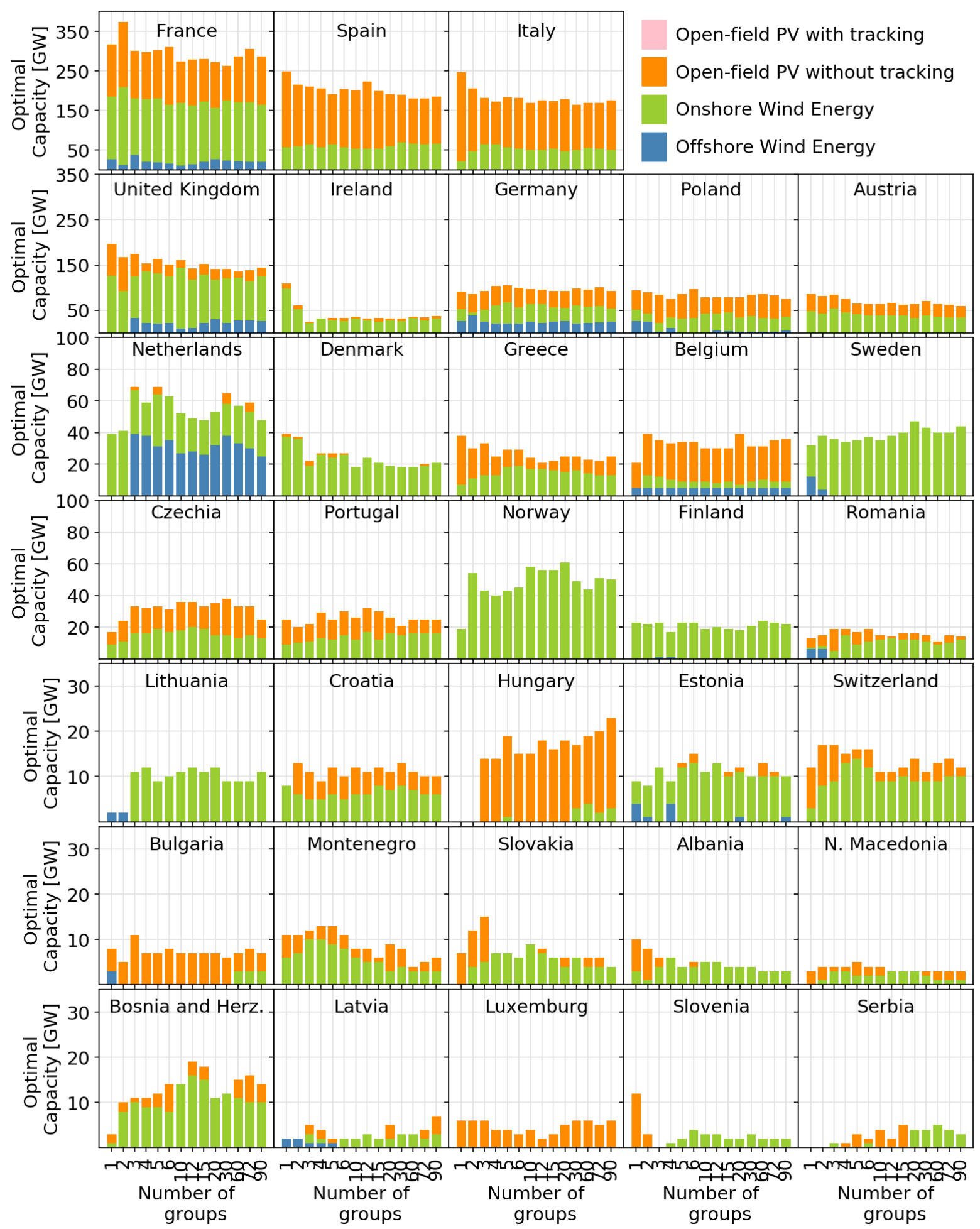

Figure 6 National optimal capacities broken down into onshore wind energy, offshore wind energy, open-field PV with tracking and open-field PV without it for different numbers of technology groups.

\subsection{Variation in Total Annual Cost by Iterations}

Figure 7 shows the distribution of total annual costs found in each weather year within the corresponding iterative step. Furthermore, the analysis indicates that only a few iterations are required in order to identify a robust system design. As can be seen from the figure, the range between the minimum and maximum total annual cost in each iteration decreases until the 
capacities of biomass are scaled (Iteration 4). The increase in the median system cost (shown as red lines in the figure) in each iteration is also evident due to the method employed in this iterative approach to obtain a robust system design. Furthermore, the comparably more pronounced increase between "Iteration 3" and "Iteration 4" can be explained through the use of time series aggregation. When time series aggregation is omitted in the system design, the impact of extreme days on the total annual cost can be clearly seen. Finally, defining the maximum capacities of biomass CHP plants over all weather years in the "Iteration 4" in the system drastically increases the total annual cost in "Iteration 5". It should be noted that the difference between the maximum and average capacities of biomass CHP plants in "Iteration 4 " is estimated as $110 \mathrm{GW}$, which increases the total annual cost by $15 \%$.

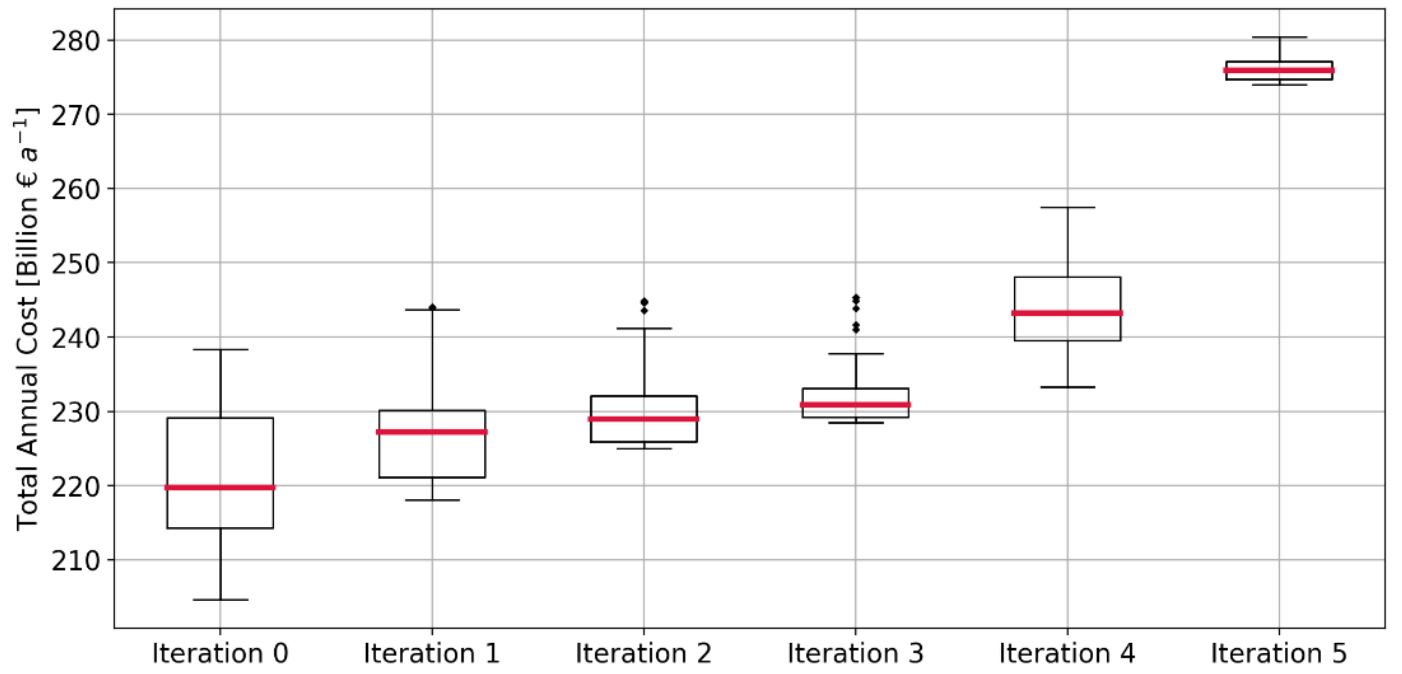

Figure 7 Total annual cost distribution as a boxplot between Iteration 0 and Iteration 5 .

\subsection{Robust European Energy System Design}

Figure 8 illustrates the energy system design obtained as a result of the iterative approach, which ensures the security of supply while decreasing the potential over-engineering of the system components. The proposed system design involves $154 \mathrm{GW}$ of biomass CHP plants, $203 \mathrm{GW}$ of hydropower plants (including run-of-river, reservoir and pumped storage), $654 \mathrm{GW}$ of openfield PV without tracking, $842 \mathrm{GW}$ of onshore wind energy and $78 \mathrm{GW}$ of offshore wind energy. Comparing the proposed capacities with the maximum capacity of each technology in "Iteration 0", it can be seen that the capacities of wind and PV are decreased by 728 and 829 $\mathrm{GW}$, respectively. Additionally, the system consists of $130 \mathrm{TWh}(0.6 \%$ of the technical potential stated by Caglayan et al. [40] and $562 \mathrm{GWh}$ of hydrogen storage in salt cavern and vessels, respectively. Batteries play a role in the system with $590 \mathrm{GWh}$ of storage capacity, especially in the regions with high PV shares to compensate the interdaily fluctuations. The storage capacities of lithium-ion batteries, gas vessels and salt caverns are significantly lower than the proposed capacities.

A comparison between the proposed robust capacities and the average capacity values independently obtained for each weather year reveals that these two capacity values are very similar, especially in Spain and France. The most substantial deviation in VRES technologies between robust system design and the averages of each weather year is observed in Slovenia, with a $65 \%$ increase in open-field PV without tracking. Slovenia is followed by Ireland, Switzerland and Latvia regarding deviations in the same technology. However, it must be noted 
that the relatively lower capacities in these countries (between 0.3 to $4 \mathrm{GW}$ ) is the main reason for this significant deviation. Nevertheless, it can be stated that the average capacities across all weather years are sufficient to supply a large portion of the demand.

In addition to the VRES technologies, a drastic increase in the biomass CHP plants is observed if a robust system design is aimed for. However, this increase is expected because of the optimization without time series aggregation and also the assigned role for biomass as a backup generation technology. All time series, including the extreme periods (i.e., peak generation or demand periods), are partly smoothened by the use of 30 typical days. As a result, these revealed extreme periods, which were not covered in the previous analyses, require a higher capacity for the biomass CHP plant, as it is the only technology allowed for the capacity expansion.

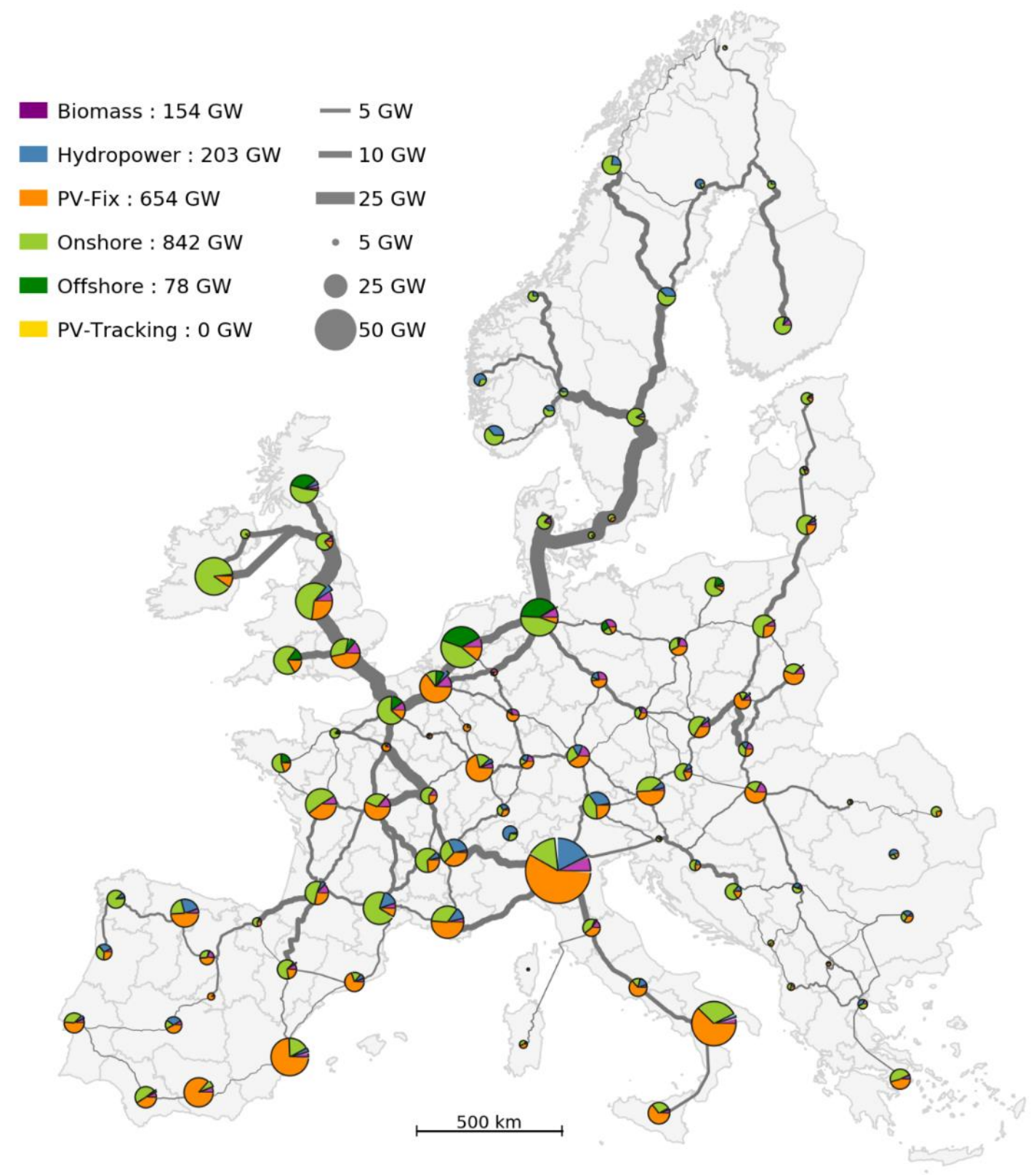

Figure 8 Proposed fully renewable European energy system design with ensured security of supply across 38 weather years. Lines represent the proposed pipeline grid. 


\subsection{Average Electricity and Hydrogen Transport between Regions}

To understand the dynamics between regions, the net annual hydrogen and electricity transport and its direction must be derived, and this is shown in Figure 9 with the flow direction. Electricity transport is estimated for both HVDC and HVAC cables, with hydrogen pipelines used for net hydrogen transport.

Focusing on electricity transport reveals the electricity flow across continental Europe in several directions. Denmark, Germany, the Netherlands and the United Kingdom import electricity from Norway owing to its locations with cheaper electricity generation. Electricity transport is evident not only from Norway but also from Finland and Sweden. However, an interesting potential electricity flow is seen in Norway with regard to regions "83_no" and "84_no". In spite of their low electricity and hydrogen demand, these regions import electricity to increase electrolyzer full load hours to produce more hydrogen. Moreover, it can be seen that Ireland and the United Kingdom supply electricity in western European countries such as France, Belgium and the Netherlands. Hence, cheap electricity generation and the transportation of it are preferred compared to the utilization of relatively more expensive locations.

The flows shown for hydrogen are relatively more succinct, with a pattern that can be easily followed. Similar behavior can be seen in the electricity flow from Nordic countries and the United Kingdom to continental Europe for hydrogen flow. With respect to hydrogen transport in the Nordic countries, it is apparent that the amount of hydrogen transport increases from the north towards the south, which indicates the accumulation of individual regional contributions being transported towards continental Europe. Once the hydrogen pipeline reaches northwestern Germany ("31_de"), it is then distributed to the neighboring regions of continental Europe. Similarly, there is large-scale hydrogen transport from the United Kingdom to "26_fr". Northern Italy is also interesting because of the hydrogen transported from France and Slovenia but exported to Austria. This is mainly because of the excess hydrogen production in the peak power generation periods via PV in Italy. Moreover, hydrogen export from Austria to southern Germany also indicates that Austria might act as a conduit in hydrogen transport to southern Germany. 


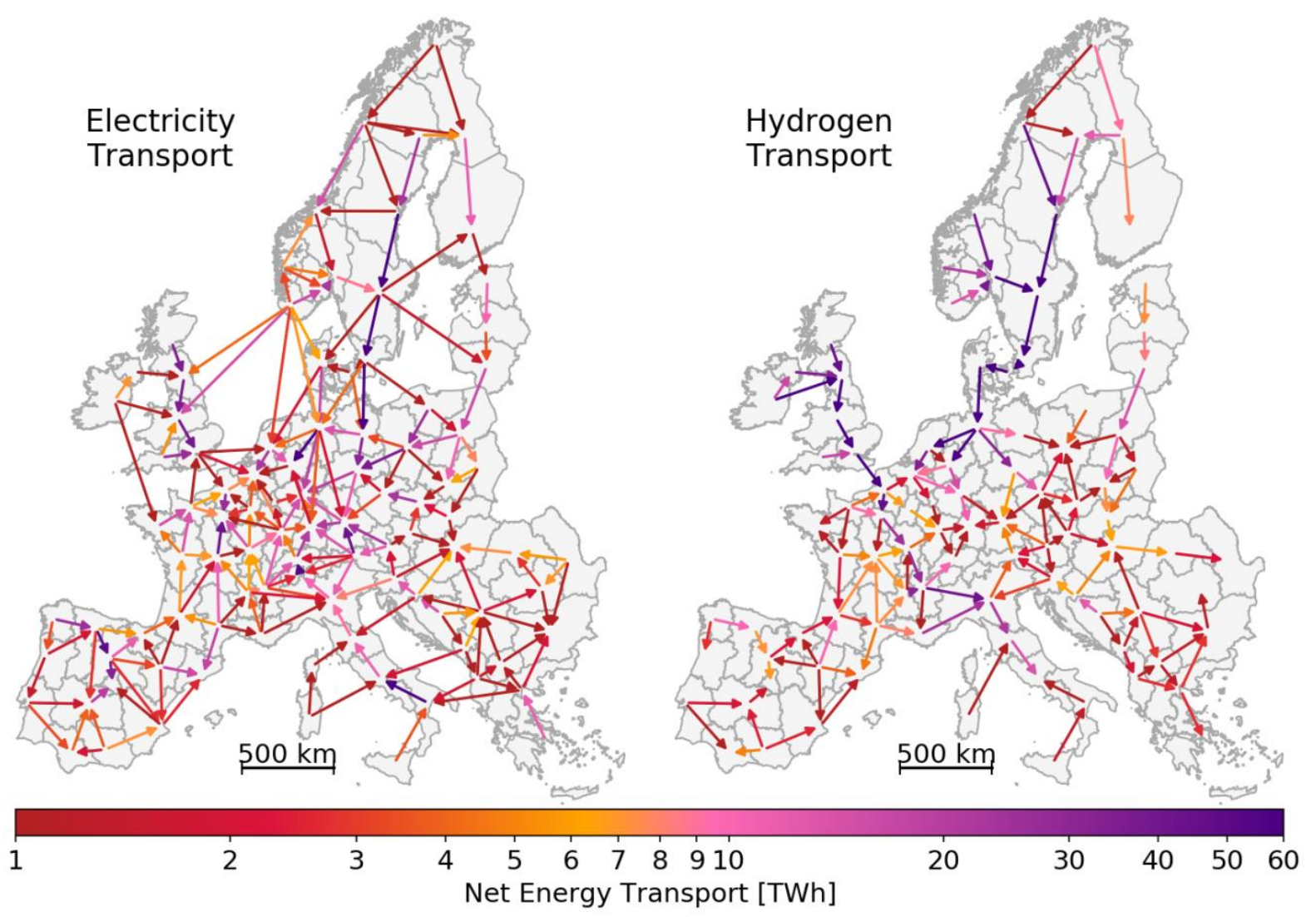

Figure 9 Net energy flow between regions for electricity (left) and hydrogen (right).

\subsection{Roles of Regions in the Robust Energy System}

In order to analyze the potential roles of European regions within the proposed future energy system, the results obtained regarding electricity and hydrogen net transport, total demand and electricity generation are used to identify four groups of countries (see Figure 10).

Both hydrogen and electricity exporters: The regions in the upper right of the figure belong to this group. As the name indicates, both commodities are exported to the neighboring regions. Ireland has the largest amount of hydrogen and electricity export, with values of $85 \mathrm{TWh} \mathrm{a}^{-1}$ and $95 \mathrm{TWh} \mathrm{a}^{-1}$, respectively. After Ireland, "94_uk", "84_no" and "15_fr" are the regions with the highest export figures.

Both hydrogen and electricity importers: Regions importing both commodities and shown in the lower left of the figure belong to this group. For instance, "92_uk", "90_uk", "33_de", "23_fr" and "52_it" constitute those regions with the highest import of electricity and hydrogen. Amongst these, "90_uk", including London, "92_uk", including Liverpool and Manchester, and "52_it", including Milan, have high demand but also high enough generation to supply the demand. Nevertheless, after the utilization of the good locations for electricity generation, the remaining areas in these regions cannot compete with the neighboring regions in terms of electricity generation costs. Therefore, some portion of the demand is supplied by generation within these regions and the remainder is imported. A different dynamic is observed in the regions "33_de" (North Rhine-Westphalia) and "23_fr" (Paris). Unlike the aforementioned regions with high imports but that still utilize the local sources, "33_de" and "23_fr" mainly supply their demand by importing electricity from most of their neighboring regions. 
Hydrogen importer - electricity exporter: This category is located in the upper left part of the figure. As can be seen, there are not many regions that import hydrogen but export electricity. The most apparent of these is northwestern Germany ("31_de"). This region exports approximately $50 \mathrm{TWh} \mathrm{a}^{-1}$ of electricity to the neighboring regions and imports almost 30 TWh $\mathrm{a}^{-1}$ of hydrogen. Although electricity transport is limited by the capacities of the HVAC and HVDC cables connecting the regions, the maximum capacity defined for hydrogen pipelines is not a limiting factor due to the relatively lower capacity requirements. In many regions, hydrogen demand is supplied by the cheapest electricity generation locations; in this specific region, it is imported from the Nordic countries. However, as the distance increases from these cheap locations (making electricity transport more difficult due to the cable capacities), utilization of the local sources becomes necessary. As a result, in "31_de", for example, both onshore and offshore wind energy is utilized due to the relatively cheaper electricity generation it offers compared to the other locations in northern continental Europe. Overall, this region imports the hydrogen produced in the north while exporting electricity generated by the local sources.

Hydrogen exporter - electricity importer: This is the group on the lower right. As is apparent, there are not many regions in this category. Nevertheless, "81_no" and "82_no" can be used as an example of it. What happens in these regions is as follows: electricity is imported to maintain reasonable full load hours for the electrolyzer and then the hydrogen produced is exported via the imported electricity. In other words, the imported electricity is not used to supply the electricity demand in these regions but to maintain electrolyzer full load hours and produce hydrogen.

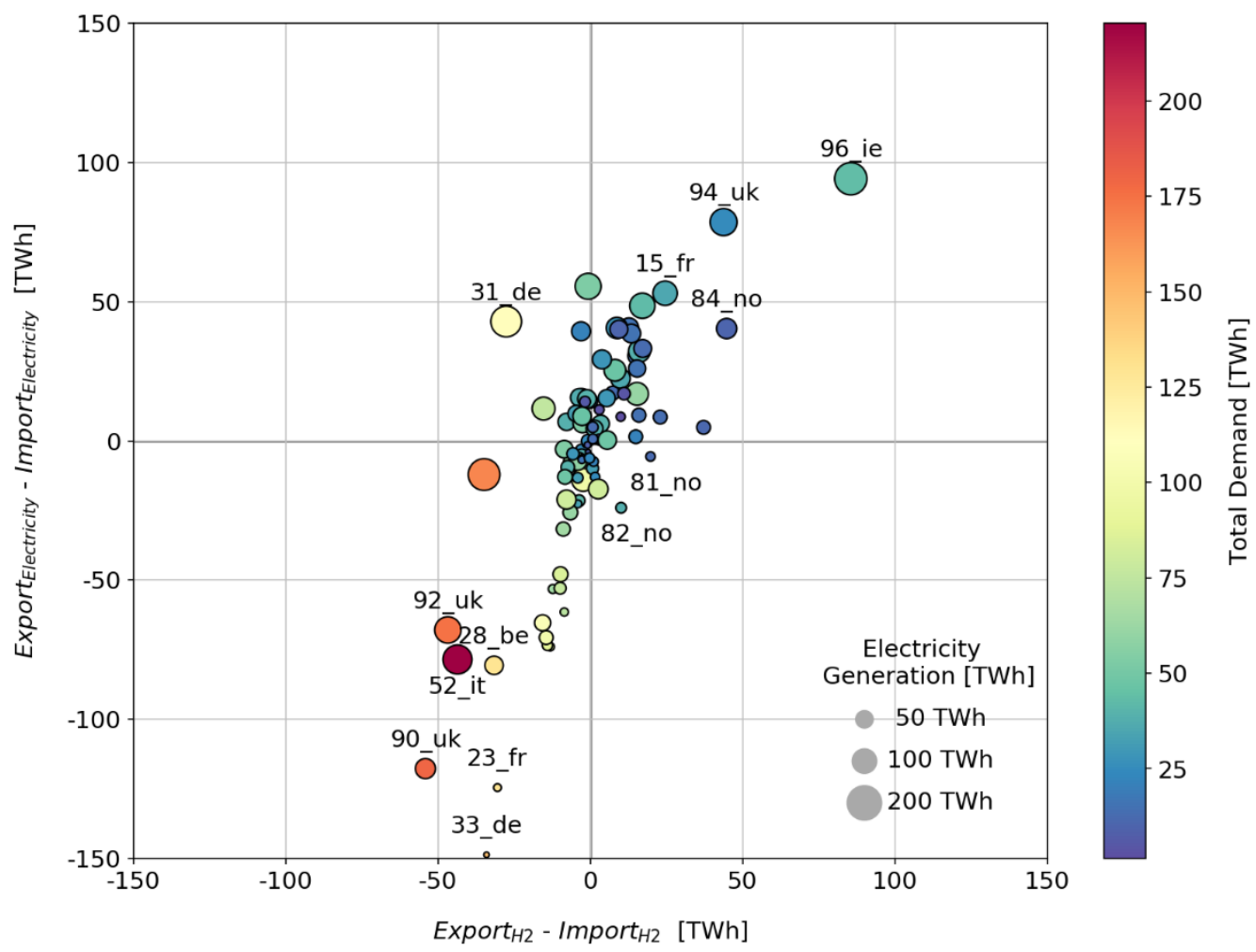

Figure 10 Net transport of electricity versus hydrogen, with electricity generation and total demand within the regions indicated as the marker size and colors, respectively. 
Another role that a region might take in terms of hydrogen can be that of a conduit. These regions can be identified by looking at the pipeline capacities and whether or not the region imports hydrogen. Correspondingly, the distribution of net hydrogen transport and the proposed pipeline connections are shown in Figure 11. Net hydrogen transport indicates the quantity of hydrogen transport, in addition to the direction of this transport via the sign. In other words, if the value is negative, hydrogen leaves the region (hydrogen export) and vice versa. Looking at the Nordic countries, larger pipeline capacities towards continental Europe can be observed. Gathering the hydrogen produced in all of regions except "75_fi" (southern Finland), a large pipeline passes through southern Sweden ("88_se" and "89_se"), which does not export a significant amount of hydrogen. Then, the connection passes by regions in Denmark with a slight increase in their capacities. Therefore, these regions do not benefit from the large hydrogen pipelines connecting them, yet serve as a conduit that enables hydrogen transport to the non-neighboring regions. The northern United Kingdom sees the same behavior, with hydrogen produced in both the United Kingdom and Ireland being transported to continental Europe via the connection between "90_uk" and " 26 fr". Then, it is distributed to the neighboring regions.

Comparison of the proposed hydrogen pipeline grid to the European hydrogen backbone [46] reveals the similarities in the connections. Some examples for these similarities are the connections between Denmark and Sweden, the Netherlands and Germany as well as Belgium. Additionally, the resemblance of pipeline grids within the countries such as Germany, Spain and Italy is evident. Nevertheless, there are some deviations in the connections. European hydrogen backbone [46] does not include the connections in the northwestern France as well as the connection between France and Italy, which are proposed in the presented assessment.

The importance of conduit regions cannot be fully conveyed in this analysis due to the perfect European market assumption made at the beginning. However, it must be noted that the negation of any of these connections would change the proposed energy system design. For instance, a public acceptance issue raised in Denmark could disconnect the Nordic regions from continental Europe. Another hindrance to these connections could be unforeseen political developments in the style of Brexit. Therefore, despite the high generation and cheaper hydrogen production potential compared to continental Europe, a more decentralized design would be required in such a case. Moreover, this would probably result in changing the roles of countries as hydrogen importers or exporters, as a new balance in the system would need to be attained. All in all, it is worth emphasizing the importance of these conduit regions in the energy system's design. 


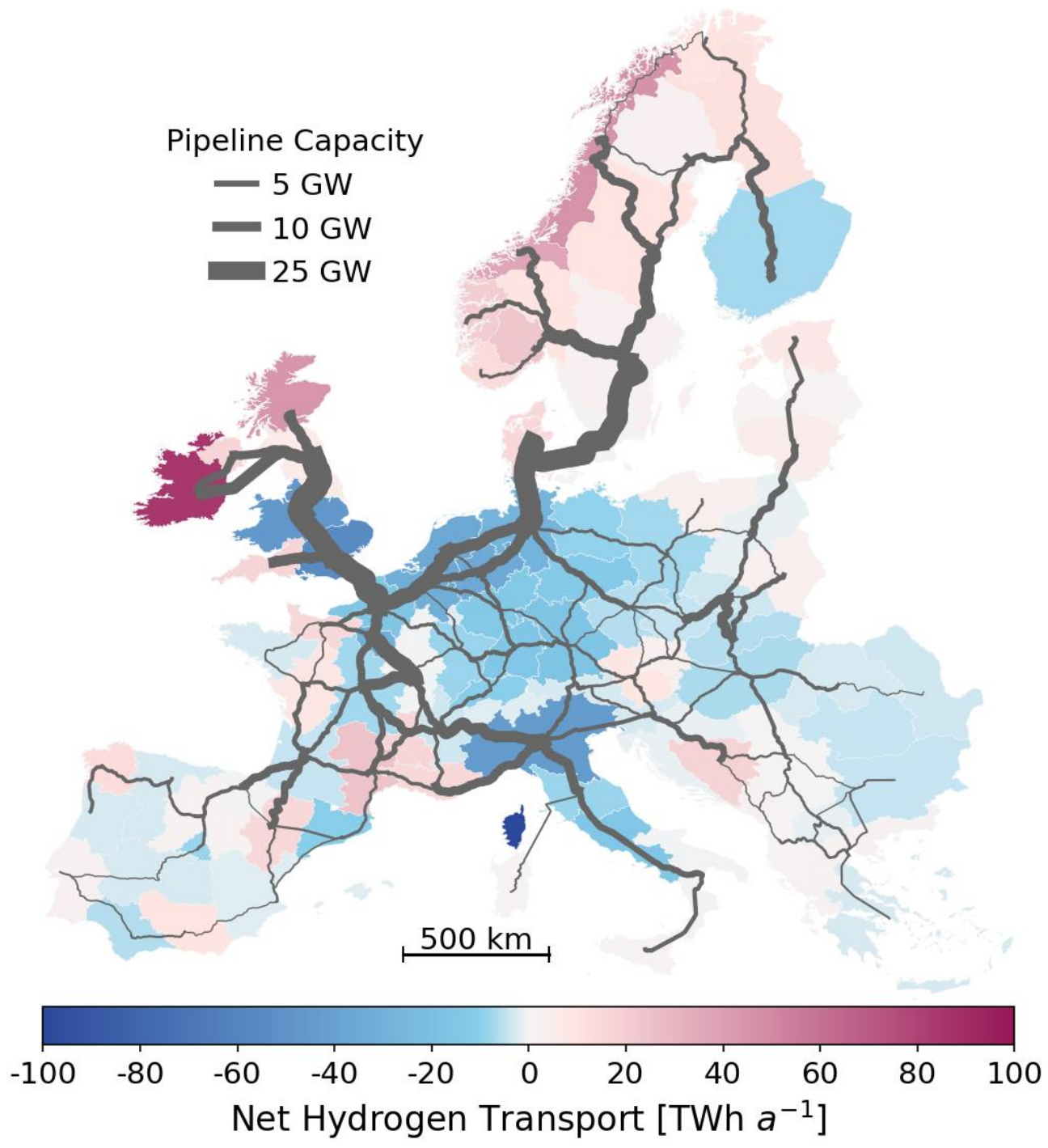

Figure 11 Geospatial distribution of the net hydrogen transport across regions with proposed pipeline connections.

\section{Summary \& Outlook}

This work proposes an iterative approach to attain a robust, fully renewable European energy system design that takes into account the high spatial resolution of renewable modeling, as well as different design results on the basis of historical weather years. The optimization model consists of 96 regions with hourly temporal resolution and takes hydrogen infrastructure into account.

Creating groups of VRES technologies increases the spatial resolution of the optimization problem, with a slight increase in the complexity compared to a higher number of regions. It can be seen that the total annual cost decreases with higher resolution due to the cheap locations identified in each region. Furthermore, these cheap locations become cost-competitive with biomass, which results in a decrease in the capacity of CHP plants required in the system. The use of 60 VRES groups per technology is found to be sufficient and represents the variability of renewables within each region.

Taking into account the annual variations and spatial variability of the renewables, an iterative approach is proposed to obtain a robust, fully renewable European energy system design. The 
design consists of $1574 \mathrm{GW}$ wind and PV capacities, $42 \%$ of which correspond to open-field PV systems. Additionally, $154 \mathrm{GW}$ of biomass CHP plants and $203 \mathrm{GW}$ of hydropower plants are incorporated in the design. The total, respective capacity of $258 \mathrm{GW}$ and $134 \mathrm{GW}$ of electrolyzers and hydrogen re-electrification technologies are also used in the model. Only $0.6 \%$ $(130 \mathrm{TWh})$ of the technical potential of salt caverns is realized for hydrogen storage, in addition to $562 \mathrm{GWh}$ and $587 \mathrm{GWh}$ of vessel and lithium-ion batteries.

When different roles are defined for the regions investigated in this analysis, it is clear that the Nordic countries, as well as Ireland and the United Kingdom, are mainly exporters in terms of hydrogen and electricity owing to the cheap cost of electricity generation in these locations. In addition to these regions, northwestern Germany and southern France are also considered exporter regions. As is expected, large demand centers, such as the regions containing London, Paris and Milan, are net electricity and hydrogen importers.

The results show that $100 \%$ renewable European energy system is feasible. It can be said that detailed assessments on the data used in the energy system design are crucial. It can be said that detailed assessments of the data used in the energy system design are crucial. Moreover, it is apparent that the iterative approach proposed in this work prevents the over-engineering of the robust system design compared to the use of maximum capacities.

\section{Acknowledgments}

This work was supported by the Helmholtz Association under the Joint Initiative, "EnergySystem 2050: A Contribution of the Research Field Energy". In addition, the authors acknowledge financial support by the Federal Ministry for Economic Affairs and Energy of Germany in the context of project METIS (project number 03ET4064A).

\section{References}

[1] European Commission. Energy Roadmap 2050. 2012. https://doi.org/10.2833/10759.

[2] European Commission. EU Reference Scenario 2016 - Energy, transport and GHG emissions - Trends to 2050. 2016. https://doi.org/10.2833/001137.

[3] Schiebahn S, Grube T, Robinius M, Tietze V, Kumar B, Stolten D. Power to gas: Technological overview, systems analysis and economic assessment for a case study in Germany. Int J Hydrogen Energy 2015;40:4285-94. https://doi.org/10.1016/j.ijhydene.2015.01.123.

[4] Robinius M, Otto A, Syranidis K, Ryberg DS, Heuser P, Welder L, et al. Linking the Power and Transport Sectors-Part 2: Modelling a Sector Coupling Scenario for Germany. Energies 2017;10:957. https://doi.org/10.3390/en10070957.

[5] Robinius M, Otto A, Heuser P, Welder L, Syranidis K, Ryberg D, et al. Linking the Power and Transport Sectors-Part 1: The Principle of Sector Coupling. Energies 2017;10:956. https://doi.org/10.3390/en10070956.

[6] Resch B, Sagl G, Törnros T, Bachmaier A, Eggers J-B, Herkel S, et al. GIS-Based Planning and Modeling for Renewable Energy: Challenges and Future Research Avenues. ISPRS Int J Geo-Information 2014;3:662-92. https://doi.org/10.3390/ijgi3020662.

[7] Ruhnau O, Bannik S, Otten S, Praktiknjo A, Robinius M. Direct or indirect electrification? A review of heat generation and road transport decarbonisation scenarios for Germany 2050. Energy 2019. https://doi.org/10.1016/j.energy.2018.10.114. 
[8] Grube T, Doré L, Hoffrichter A, Hombach LE, Raths S, Robinius M, et al. An option for stranded renewables: Electrolytic-hydrogen in future energy systems. Sustain Energy Fuels 2018. https://doi.org/10.1039/c8se00008e.

[9] IRENA. Hydrogen from renewable energy: Technology outlook for the energy transition. Abu Dhabi: 2018.

[10] Quarton CJ, Tlili O, Welder L, Mansilla C, Blanco H, Heinrichs H, et al. The curious case of the conflicting roles of hydrogen in global energy scenarios. Sustain Energy Fuels 2020;4:80-95. https://doi.org/10.1039/C9SE00833K.

[11] Dolci F, Thomas D, Hilliard S, Guerra CF, Hancke R, Ito H, et al. Incentives and legal barriers for power-to-hydrogen pathways: An international snapshot. Int J Hydrogen Energy 2019. https://doi.org/10.1016/j.ijhydene.2019.03.045.

[12] Samsatli S, Staffell I, Samsatli NJ. Optimal design and operation of integrated windhydrogen-electricity networks for decarbonising the domestic transport sector in Great Britain. Int J Hydrogen Energy 2016;41:447-75. https://doi.org/10.1016/j.ijhydene.2015.10.032.

[13] Tlili O, Mansilla C, Robinius M, Syranidis K, Reuss M, Linssen J, et al. Role of electricity interconnections and impact of the geographical scale on the French potential of producing hydrogen via electricity surplus by 2035. Energy 2019;172:977-90. https://doi.org/10.1016/j.energy.2019.01.138.

[14] Guandalini G, Robinius M, Grube T, Campanari S, Stolten D. Long-term power-to-gas potential from wind and solar power: A country analysis for Italy. Int J Hydrogen Energy 2017. https://doi.org/10.1016/j.ijhydene.2017.03.081.

[15] Welder L, Ryberg DS, Kotzur L, Grube T, Robinius M, Stolten D. Spatio-temporal optimization of a future energy system for power-to-hydrogen applications in Germany. Energy 2018;158:1130-49. https://doi.org/10.1016/j.energy.2018.05.059.

[16] Reuß M, Grube T, Robinius M, Stolten D. A hydrogen supply chain with spatial resolution: Comparative analysis of infrastructure technologies in Germany. Appl Energy 2019. https://doi.org/10.1016/j.apenergy.2019.04.064.

[17] Heuser PM, Ryberg DS, Grube T, Robinius M, Stolten D. Techno-economic analysis of a potential energy trading link between Patagonia and Japan based on $\mathrm{CO} 2$ free hydrogen. Int J Hydrogen Energy 2019. https://doi.org/10.1016/j.ijhydene.2018.12.156.

[18] Reichenberg L, Hedenus F, Odenberger M, Johnsson F. The marginal system LCOE of variable renewables - Evaluating high penetration levels of wind and solar in Europe. Energy 2018;152:914-24. https://doi.org/10.1016/j.energy.2018.02.061.

[19] Aboumahboub T, Tzscheutschler P, Hamacher T. Optimizing World-wide Utilization of Renewable Energy Sources in the Power Sector. Renew Energy Power Qual J 2010;1:15-21. https://doi.org/10.24084/repqj08.207.

[20] Brown T, Schlachtberger D, Kies A, Schramm S, Greiner M. Synergies of sector coupling and transmission reinforcement in a cost-optimised, highly renewable European energy system. Energy 2018;160:720-39. https://doi.org/10.1016/j.energy.2018.06.222.

[21] Pavičević M, Mangipinto A, Nijs W, Lombardi F, Kavvadias K, Jiménez Navarro JP, et al. The potential of sector coupling in future European energy systems: Soft linking between the Dispa-SET and JRC-EU-TIMES models. Appl Energy 2020;267:115100. 
https://doi.org/10.1016/j.apenergy.2020.115100.

[22] Lux B, Pfluger B. A supply curve of electricity-based hydrogen in a decarbonized European energy system in 2050. Appl Energy 2020;269:115011. https://doi.org/10.1016/j.apenergy.2020.115011.

[23] Siala K, Mahfouz MY. Impact of the choice of regions on energy system models. Energy Strateg Rev 2019;25:75-85. https://doi.org/10.1016/j.esr.2019.100362.

[24] Siala K, de la Rúa C, Lechón Y, Hamacher T. Towards a sustainable European energy system: Linking optimization models with multi-regional input-output analysis. Energy Strateg Rev 2019;26:100391. https://doi.org/10.1016/j.esr.2019.100391.

[25] Zappa W, Junginger M, van den Broek M. Is a 100\% renewable European power system feasible by 2050? Appl Energy 2019;233-234:1027-50. https://doi.org/10.1016/j.apenergy.2018.08.109.

[26] Steinke F, Wolfrum P, Hoffmann C. Grid vs. storage in a 100\% renewable Europe. Renew Energy 2013;50:826-32. https://doi.org/10.1016/j.renene.2012.07.044.

[27] Moser M, Gils H-C, Pivaro G. A sensitivity analysis on large-scale electrical energy storage requirements in Europe under consideration of innovative storage technologies. J Clean Prod 2020;269:122261. https://doi.org/10.1016/j.jclepro.2020.122261.

[28] Bussar C, Moos M, Alvarez R, Wolf P, Thien T, Chen H, et al. Optimal Allocation and Capacity of Energy Storage Systems in a Future European Power System with $100 \%$ Renewable Energy Generation. Energy Procedia 2014;46:40-7. https://doi.org/10.1016/j.egypro.2014.01.156.

[29] Bussar C, Stöcker P, Cai Z, Moraes Jr. L, Magnor D, Wiernes P, et al. Large-scale integration of renewable energies and impact on storage demand in a European renewable power system of 2050 - Sensitivity study. J Energy Storage 2016;6:1-10. https://doi.org/10.1016/j.est.2016.02.004.

[30] Bussar C, Stöcker P, Cai Z, Moraes L, Alvarez R, Chen H, et al. Large-scale Integration of Renewable Energies and Impact on Storage Demand in a European Renewable Power System of 2050. Energy Procedia 2015;73:145-53. https://doi.org/10.1016/j.egypro.2015.07.662.

[31] Löffler K, Burandt T, Hainsch K, Oei P-Y. Modeling the low-carbon transition of the European energy system - A quantitative assessment of the stranded assets problem. Energy Strateg Rev 2019;26:100422. https://doi.org/10.1016/j.esr.2019.100422.

[32] Schlott M, Kies A, Brown T, Schramm S, Greiner M. The impact of climate change on a cost-optimal highly renewable European electricity network. Appl Energy 2018;230:1645-59. https://doi.org/10.1016/j.apenergy.2018.09.084.

[33] Child M, Kemfert C, Bogdanov D, Breyer C. Flexible electricity generation, grid exchange and storage for the transition to a $100 \%$ renewable energy system in Europe. Renew Energy 2019;139:80-101. https://doi.org/10.1016/j.renene.2019.02.077.

[34] Bogdanov D, Farfan J, Sadovskaia K, Aghahosseini A, Child M, Gulagi A, et al. Radical transformation pathway towards sustainable electricity via evolutionary steps. Nat Commun 2019;10:1077. https://doi.org/10.1038/s41467-019-08855-1.

[35] Caglayan DG, Heinrichs HU, Stolten D, Robinius M. The Impact of Temporal Complexity Reduction on a 100\% Renewable European Energy System with Hydrogen 
Infrastructure.

Preprints

2019;2019100150.

https://doi.org/10.20944/preprints201910.0150.v1.

[36] Caglayan DG, Heinrichs HU, Linssen J, Robinius M, Stolten D. Impact of different weather years on the design of hydrogen supply pathways for transport needs. Int J Hydrogen Energy 2019;44:25442-56. https://doi.org/10.1016/J.IJHYDENE.2019.08.032.

[37] Pfenninger S. Dealing with multiple decades of hourly wind and PV time series in energy models: A comparison of methods to reduce time resolution and the planning implications of inter-annual variability. Appl Energy 2017;197:1-13. https://doi.org/10.1016/j.apenergy.2017.03.051.

[38] Kotzur L, Markewitz P, Robinius M, Stolten D. Time series aggregation for energy system design: Modeling seasonal storage. Appl Energy 2018;213:123-35. https://doi.org/10.1016/j.apenergy.2018.01.023.

[39] Bruninx K, Orlic D, Couckuyt D, Grisey N, Betraoui B, Anderski T, et al. Modular Development Plan of the Pan-European Transmission System 2050 - D2.1: Data sets of scenarios for 2050. 2015.

[40] Caglayan DG, Weber N, Heinrichs HU, Linßen J, Robinius M, Kukla PA, et al. Technical potential of salt caverns for hydrogen storage in Europe. Int J Hydrogen Energy 2020;45:6793-805. https://doi.org/10.1016/j.ijhydene.2019.12.161.

[41] Rienecker MM, Suarez MJ, Gelaro R, Todling R, Bacmeister J, Liu E, et al. MERRA: NASA's Modern-Era Retrospective Analysis for Research and Applications. J Clim 2011;24:3624-48. https://doi.org/10.1175/JCLI-D-11-00015.1.

[42] Ryberg DS, Heinrichs HU, Robinius M, Stolten D. RESKit - Renewable Energy Simulation toolkit for Python 2019. https://github.com/FZJ-IEK3-VSA/RESKit.

[43] Ryberg DS, Caglayan DG, Schmitt S, Linßen J, Stolten D, Robinius M. The future of European onshore wind energy potential: Detailed distribution and simulation of advanced turbine designs. Energy 2019;182:1222-38. https://doi.org/10.1016/j.energy.2019.06.052.

[44] Ryberg DS. Generation Lulls from the Future Potential of Wind and Solar Energy in Europe. RWTH Aachen University, 2019.

[45] Caglayan DG, Ryberg DS, Heinrichs H, Linßen J, Stolten D, Robinius M. The technoeconomic potential of offshore wind energy with optimized future turbine designs in $\begin{array}{lll}\text { Europe. Appl 2019;255:113794. } & \text { Energy }\end{array}$ https://doi.org/10.1016/j.apenergy.2019.113794.

[46] Wang A, Leun K van der, Peters D, Buseman M. European Hydrogen Backbone. Utrecht: 2020. 